\title{
CORRECTION
}

\section{Correction to: Inert gas narcosis in scuba diving, different gases different reactions}

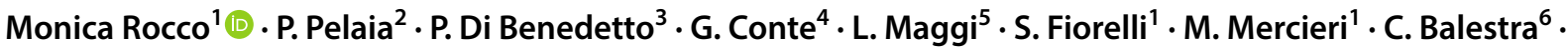 \\ R. A. De Blasi ${ }^{1}$ on behalf of ROAD Project Investigators
}

Published online: 19 April 2019

๑) Springer-Verlag GmbH Germany, part of Springer Nature 2019

\section{Correction to: \\ European Journal of Applied Physiology (2019) 119:247-255 \\ https://doi.org/10.1007/s00421-018-4020-y}

The original version of this article unfortunately contained a mistake. Collaborator (Scaradozzi D) name was incorrect in the Acknowledgements section. The correct information is given below.

Acknowledgements ROAD Project Investigators include: Scaradozzi D, Gala F, Screpanti L, Argentario Diving, Nicolini S, Mesa S.
Publisher's Note Springer Nature remains neutral with regard to jurisdictional claims in published maps and institutional affiliations.

The original article can be found online at https://doi.org/10.1007/ s00421-018-4020-y.

Monica Rocco

monica.rocco@uniroma1.it

1 Department of Surgical and Medical Science

and Translational Medicine, Anesthesia and Intensive Care,

Sapienza University, Rome, Italy

2 Department of Biomedical Sciences and Public Health, Anesthesia and Intensive Care, Università Politecnica delle Marche Torrette, Ancona, Italy

3 Azienda Ospedaliero, Universitaria Sant'Andrea, Rome, Italy

4 Department of Informatics Engineering, University

Politecnica delle Marche, Ancona, Italy

5 Anesthesia and Intensive Care, Università Campus Biomedico, Rome, Italy

6 Environmental, Occupational and Ageing (Integrative) Physiology Lab, Haute Ecole Bruxelles-Brabant (HE2B), Brussels, Belgium 